\title{
Safe and feasible inflow occlusion in laparoscopic liver resection
}

\author{
Akihiro Cho · Hiroshi Yamamoto · Matsuo Nagata • \\ Nobuhiro Takiguchi · Hideaki Shimada - Osamu Kainuma • \\ Hiroaki Souda · Hisashi Gunji · Akinari Miyazaki · \\ Atsushi Ikeda
}

Published online: 18 August 2009

(C) Springer Science+Business Media, LLC 2009

We have described a laparoscopic technique for encircling the hepatoduodenal ligament using an Endo Retract Maxi as a tourniquet for complete interruption of blood inflow to the liver [1]. Belli et al. [2] stressed that this technique is not new because several years ago they started to encircle the hepatoduodenal ligament with vessel tape using an Endo Retract Maxi. Indeed, they described the same technique for performing a laparoscopic Pringle's maneuver [3]. However, for several years, we also had used an Endo Retract Maxi to encircle not only the hepatoduodenal ligament but also the Glissonean pedicles [4].

Recently, laparoscopic liver resection has become rapidly accepted as an alternative to conventional open liver resection. We should be aware that laparoscopic liver surgery still presents severe technical difficulties, such as control of massive hemorrhage. Intraoperative inflow occlusion of the liver should thus be recommended to reduce blood loss during laparoscopic liver resection. We do not wish to maintain that this technique is new, but rather to report that laparoscopic encircling of the hepatoduodenal ligament using an Endo Retract Maxi can be performed easily and rapidly even by surgeons with minimal or no laparoscopic experience.

\section{References}

1. Cho A, Yamamoto H, Nagata M, Takiguchi N, Shimada H, Kainuma O, Souda H, Gunji H, Miyazaki A, Ikeda A, Matsumoto I (2009) Safe and feasible inflow occlusion in laparoscopic liver resection. Surg Endosc 23:906-908

2. Belli G, Fantini C, D’Agostino A, Cioffi L, Limongelli P, Russo G, Belli A (2009) Re: safe and feasible inflow occlusion in laparoscopic liver resection. Surg Endosc 23:1686

3. Belli G, Fantini C, D’Agostino A, Cioffi L, Limongelli P, Russo G, Belli A (2008) Laparoscopic segment VI liver resection using a left lateral decubitus position: a personal modified technique. J Gastrointest Surg 12:2221-2226

4. Cho A, Asano T, Yamamoto H, Nagata M, Takiguchi N, Kainuma O, Souda H, Gunji H, Miyazaki A, Nojima H, Ikeda A, Matsumoto I, Ryu M, Makino H, Okazumi S (2007) Laparoscopy-assisted hepatic lobectomy using hilar Glissonean pedicle transection. Surg Endosc 21:1466-1468
A. Cho $(\varangle) \cdot$ H. Yamamoto $\cdot$ M. Nagata $\cdot$ N. Takiguchi $\cdot$

H. Shimada $\cdot$ O. Kainuma $\cdot$ H. Souda $\cdot$ H. Gunji .

A. Miyazaki · A. Ikeda

Division of Gastroenterological Surgery, Chiba Cancer Center

Hospital, 666-2 Nitonachou, Chuouku, Chiba 260-8717, Japan

e-mail: acho@chiba-cc.jp 